American Journal of Environmental Sciences 4 (3): 178-184, 2008

ISSN 1553-345X

(C) 2008 Science Publications

\title{
Hydropower System Management Considering the Minimum Outflow
}

\author{
M. L. Arganis and R. Domínguez \\ Instituto de Ingeniería, Universidad Nacional Autónoma de México, Ciudad Universitaria Circuito \\ Escolar s/n Edificio 5, Delegación Coyoacán. México 04510, D.F.
}

\begin{abstract}
This paper deals with the operating rules of the Grijalva River hydropower serial system obtained by means of stochastic dynamic programming and its subsequent simulation using historical records and synthetic series. Penalties in spills and deficit were considered in optimum policies. During simulation several restrictions were added to the original problem, particularly to ensure minimum outflow so as to guarantee the ecological river flow, which enables operators to adjust energy at daily demands peak and consider the existing autocorrelation between biweekly volume data
\end{abstract}

Keywords: stochastic dynamic programming, operating rules, serial dams, autocorrelation

\section{INTRODUCTION}

Ecological hydrology has become an important tool to be taken into account in water management ${ }^{[1,2]}$. Hydropower management has several implications: on one hand, it produces clean power, few greenhouse emissions, no fossil fuel is used, etc. On the other hand, it also generates ecological changes and damages the surrounding environment before, during, and after its operation $^{[3,6]}$.

Several research projects have been undertaken over the last two decades, so as to develop qualitative techniques to generate the minimum flow required for acceptable ecologic survival, if such a term is acceptable. This multidisciplinary subject is expanding and more people in the world are increasingly concerned about it ${ }^{[7-11]}$.

Hydropower systems in developing countries are commonly used mainly for daily peak demands. If the dam is located upstream, a set of rural and urban areas or even green areas or crop areas, as well as ecosystems could suffer significant damage due to river flow, which is subject to the dam's operating rules.

Operating rules depend on the random nature of reservoir inflows, the time of year, dry and rainy seasons, dam operating design levels, etc., but they are strongly related to political issues involving decisionmakers and operators' needs. A lot of studies can be performed, but if they are not put into practice, they remain as mere theoretical responses to real problems and almost tantamount to doing nothing at all.

\section{MATERIALS AND METHODS}

Site description: The Grijalva River rises in Guatemala and flows through Mexico's Chiapas State and into Tabasco State where it joins the Usumacinta River, and it finally empties into the Gulf of Mexico (Fig.1).

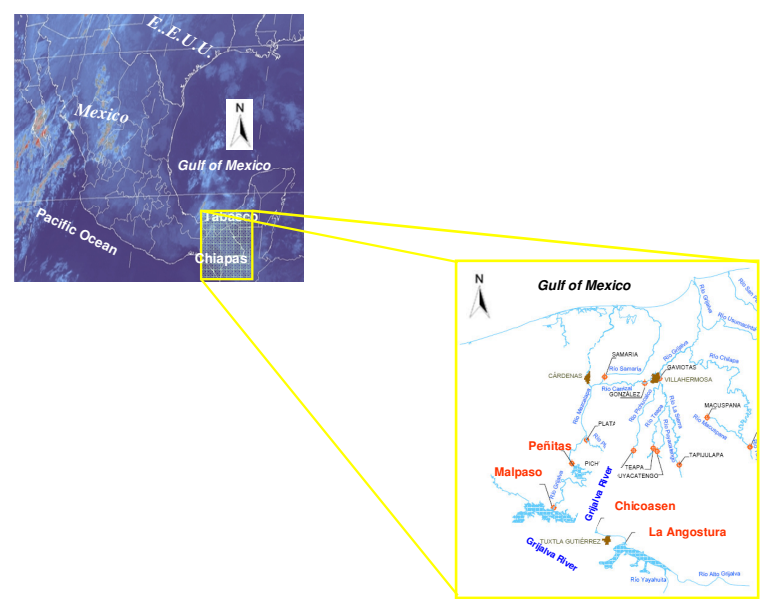

Fig. 1: Grijalva River, Mexico

Before the fifties, the Grijalva River caused continuous flooding in Tabasco's plain zone.

However, the Operator Organism Comisión Federal de Electricidad (CFE) has performed studies related to the Grijalva River's hydroelectric potential since 1958. In coordination with Secretaría de Recursos Hidráulicos (known today as the Comisión Nacional

del Agua, CONAGUA), the CFE subsequently drew up the Grijalva Comprehensive Plan.

Corresponding Author: M. L. Arganis, N Instituto de Ingeniería, Universidad Nacional Autónoma de México, Ciudad Universitaria Circuito Escolar s/n Edificio 5 Cub.414-F, Delegación Coyoacán. México 04510, D.F. Tel 525556233600 Ext. 8636 Fax: 56162798. 
The hydropower serial system is comprised of the La Angostura Dam (Belisario Domínguez), built between 1969 and 1975; the Chicoasen Dam (Manuel Moreno Torres), built between 1977 and 1983, as well as the Malpaso Dam (Netzahualcoyotl), built between 1959 and 1964, and the Peñitas Dam (Angel Albino Corzo), which was completed in 1987. Figure 2 shows a schematic profile of these dams.

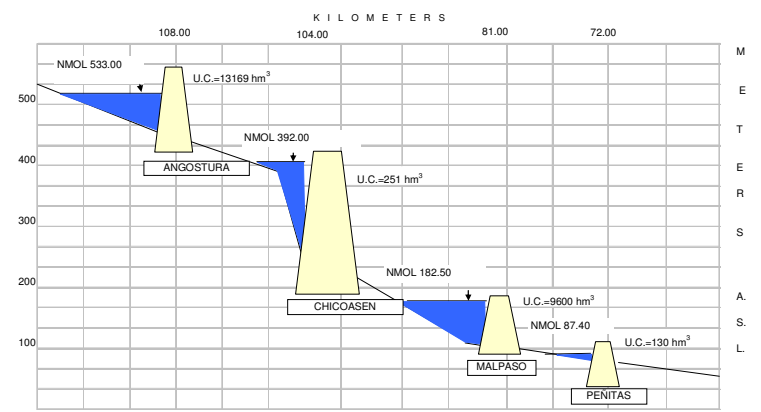

Fig. 2: Profile of the Grijalva hydropower serial system, Mexico

The dams produced very significant changes in the flow of water through the riverbed, flooded very big areas while artificial reservoirs were created. This brought the most important benefits to the country for electric purposes; but with their consequential changes to the environment and surrounding areas.

Stochastic dynamic programming: There are various useful optimization techniques in literature intended to gain optimal control over a system, such as linear programming ${ }^{[12-14]}$, nonlinear programming ${ }^{[15]}$, dynamic programming, special forms in dynamic programming, deterministic or stochastic dynamic programming, evolutive computing, simulated annealing, dynamic programming with fuzzy rules ${ }^{[16-23]}$, etc., but many of these methods are not actually used for practical purposes. This poses a challenge which engineers and decision-makers have to take into account if really they intend to solve nature and human needs.

In this document, stochastic dynamic programming was applied based on variables

involved in the problem. This method defines the feasible optimum control based on Bellman's optimum principle, "An optimum policy has the next property: no matter whatever state or initial decisions has been taken, the remaining decisions must

constitute an optimum policy independently of the resulting state of the first decision". This sequential nature, marked by interdependent decisions, allows the operating rules of storage dams to take full advantage of the algorithm methodology, through the use of dynamic programming.
The intended function was to maximize the expected value of a long term benefit, imposing some penalty coefficients in each spill or deficit of an equivalent system consisting of two reservoirs with the greatest useful reservoir capacity (UC), in this case, La Angostura and Malpaso dams ${ }^{[24]}$. The following was proposed:

$$
\begin{aligned}
F O= & \operatorname{MaxE}\left(G_{\text {Ang }}+G_{\text {Malp }}-C_{1} \operatorname{Derr}_{\text {Ang }}-\right. \\
& \left.C_{2} \operatorname{Derr}_{\text {Malp }}-C_{3} \operatorname{Def}_{\text {Ang }}-C_{4} \operatorname{Def}_{\text {Malp }}\right)
\end{aligned}
$$

Where: $F O$ objective function, $E()$ expected operator, $G_{\text {Ang }}$ generated energy from the La Angostura dam, $G_{\text {Malp }}$ generated energy from the Malpaso dam, $C_{l}$ Derr $_{\text {Ang }}$ penalty coefficient from the spills in La Angostura, $C_{2}$ Derr $_{\text {Malp }}$ penalty coefficient from spills in Malpaso, $C_{3} D e f_{\text {Ang }}$, penalty coefficient from the deficit in La Angostura, $C_{4} D e f_{\text {Malp }}$, penalty coefficient from the deficit in Malpaso.

Each dam is subject to: continuity: $j=i+x-k$; estates: 1 $\leq j \leq N S$, inflows: $1 \leq x \leq n x$; extraction: $k_{\min } \leq k \leq$ $k_{\max }$.

Stochastic dynamic programming assumes a) random inflows associated to a probability density function $f(x)$, b) dependent operation in system reservoirs. To get the maximum expected value from benefit equations, 2 and 3 are applied:

$$
\begin{aligned}
& B_{n}^{K_{1}, K_{2}}\left(i_{1}, i_{2}\right)=\sum_{j_{1}=1}^{N S_{1}} \sum_{j_{2}=1}^{N S_{2}} q_{n, K_{1}}\left(i_{1}, j_{1}\right) q_{n, k_{2}}\left(i_{2}, j_{2}\right)\{ \\
& \left.\quad\left[b_{n, K_{1}}\left(i_{1}, j_{1}\right)+b_{n, K_{1}, K_{2}}\left(i_{1}, j_{1}, i_{2}, j_{2}\right)\right]+B_{n+1}^{*}\left(j_{1}, j_{2}\right)\right\}
\end{aligned}
$$

And:

$$
B_{n}^{*}\left(i_{1}, i_{2}\right)=\max _{k_{1}, k_{2}}\left\{B_{n}^{k, k_{2}}\left(i_{1}, i_{2}\right\}\right.
$$

Where: $B_{n}^{K_{1}, K_{2}}\left(i_{1}, i_{2}\right)$ benefits up to stage $n$, given operating rules $K_{1}, K_{2}, q_{n, K_{1}}\left(i_{1}, j_{1}\right) q_{n, k_{2}}\left(i_{2}, j_{2}\right)$, transition probability, $B_{n+1}^{*}\left(j_{1}, j_{2}\right)$, optimum

expected value, up to stage $n+1$, corresponding to the optimal extraction $K^{*}$.

In order to optimize the number of calculations, equation 2 is reexpressed by equations 4 and 5 :

$$
\begin{aligned}
& B_{n}^{K_{1}, K_{2}}=\phi_{n, K_{1}, K_{2}}\left(i_{1}, i_{2}\right)+ \\
& +\sum_{j_{1}=1}^{N S_{1}} \sum_{J_{2}=1}^{N S_{2}} q_{n, K_{l}}\left(i_{1}, j_{1}\right) q_{n, K_{2}}\left(i_{2}, j_{2}\right) B_{n+1}^{*}\left(j_{1}, j_{2}\right)
\end{aligned}
$$




$$
\begin{array}{r}
\phi_{n, K_{1}, K_{2}}\left(i_{1}, i_{2}\right)=\sum_{j_{1}=1}^{N S_{1}} q_{n, K_{1}}\left(i_{1}, j_{1}\right) b_{n, K_{1}}\left(i_{1}, j_{1}\right)+ \\
+\sum_{j_{2}=1}^{N S_{2}} q_{n, K_{2}}\left(i_{2}, j_{2}\right) b_{n, K_{1}, K_{2}}\left(i_{1}, j_{1}, i_{2}, j_{2}\right)
\end{array}
$$

In order to solve the system form by equations 3 and 4, the next steps are followed:

1. Expected values from benefit, from each stage $\phi_{n, K_{1}, K_{2}}\left(i_{1}, i_{2}\right)$ are calculated with equation 5 (they are cyclic).

2. A very big $N$ value is assumed

3. The calculations begins with the last year $(n=N)$ assuming $B^{*}=0$ when $n=N$

4. Equation 4 is applied several times up to the sum of benefit increments between two consecutive stages that are practically the same.

5. Computing $K^{*}$ for each dam with the $B^{*}$ is calculated in step 5 .

Variation in extraction volume in terms of the autocorrelation between inflows: Intending to get better answers given by simulation in Malpaso spills with synthetic longer than the historical records, a coefficient affecting the added or extracted volume dictated by optimum operating rule on each dam was included. The original equation was:

$$
\begin{aligned}
D E L V O L_{\text {dam }, i}= & P E N D_{\text {dam }, i-2} \\
& \left(I N G H Q_{\text {dam }, \text { year }, i-2}-\operatorname{VIMED}_{\text {dam }, i-2}\right)
\end{aligned}
$$

Where: $P E N D$ is the gradient of the linear regression between month $j+1$ and month $j$ volumes, INGHQ is the fifteen day inflow, $\mathrm{hm}^{3}$; dam is a counter that takes the value of 1 for La Angostura dam and 2 for Malpaso dam. Year is a counter which indicates the year of the analysis; $i$ is the counter which varies according with the number of fortnights, that is, $i=1,2, \ldots 24$. VIMED is the mean fifteen day inflow

volume (approximated as the monthly mean divided by two), $\mathrm{hm}^{3} . D E L V O L$ is the volume increase, positive or negative, depending on the higher or lower inflow with respect to the mean value. Therefore, the resulting volume to extract is:

$$
G E X T Q_{\text {dam }, i}=G E X T Q_{\text {dam }, i}^{*}+D E L V O L_{d a m, i}
$$

Where: GEXTQ ${ }^{*}$ is the extracting volume from the optimum operating rule obtained with stochastic dynamic programming, GEXTQ is the extracting volume which includes the existing correlation between inflows volumes.

Furthermore, a coefficient affecting such a DELVOL value was added to each dam, which provides an opportunity to extract a bigger or smaller DELVOL value. Equation 6 is transformed into:

$$
\begin{aligned}
D E L V O L_{\text {dam }, i}= & C D V_{\text {dam }} P E N D_{\text {dam }, i-2} \\
& \left(I N G H Q_{\text {dam }, \text { year }, i-2}-\operatorname{VIMED}_{\text {dam }, i-2}\right)
\end{aligned}
$$

Where $C D V_{\text {dam }}$ is a coefficient greater or equal to zero that multiplies extraction volume DELVOL applied to the La Angostura or Malpaso dam.

Table 1: Over storage comparison

\begin{tabular}{ccc}
\hline Dam & $\begin{array}{c}\text { Real over storage } \\
\text { in } 1999 \\
\left(\mathrm{hm}^{3}\right)\end{array}$ & $\begin{array}{c}\text { Simulated over storage } \\
\text { in } 1999\left(\mathrm{hm}^{3}\right)\end{array}$ \\
\hline La Angostura & 3059.0 & 1219.1 \\
Malpaso & 356 & 727.7 \\
\hline
\end{tabular}

\section{RESULTS AND DISCUSSION}

In 1993 the Instituto de Ingeniería of the Universidad Nacional Autónoma de Mexico (IIUNAM) developed a study ${ }^{[25]}$ defining optimal operating rules for the La Angostura and Malpaso dams. Later, that analysis was complemented ${ }^{[26]}$ in order to obtain whole operating rules; that is, policies were monthly extractions that were defined in both dams, as a function in both reservoirs of the ending storage in the prior month.

In 1999 an extraordinary flood took place in the basin, which generated very large amounts stored, as much in La Angostura as in Malpaso. This involved very important volumes above the maximum operation levels in such a way in La Angostura, whose normal operating level (NMOL) is 533.0 above the sea level (ASL). This corresponds to a useful capability of 13200 $\mathrm{hm}^{3}$, and storage of $16259.00 \mathrm{hm}^{3}$ which mean 3050.00 $\mathrm{hm}^{3}$ above the previously established NMOL was reached. With respect to Malpaso, the NMOL corresponds to an elevation of 182.5 ASL, with a useful capacity of $9600 \mathrm{hm}^{3}$. Storage reached was $9956 \mathrm{hm}^{3}$, which exceeded the previous NMOL by $356 \mathrm{hm}^{3}$. Faced with this situation, simulations were made using operating rules obtained by II-UNAM (Table 1).

Results in Table 1 showed a lower over storage if those policies had been applied.

Including minimum outflow in rule operation: Two problems were identified during the studies about operating rules of the Grijalva River's serial dam system with stochastic dynamic programming.

The first problem occurred when the results of a policy, which maximizes generated energy and minimizes spills, were shown to the operators of the reservoirs. The policy they set was good, but it would be better if they could provide minimum generation during the draw periods and concentrate more on generation in hours of maximum demand. 
Am. J. Environ. Sci., 4 (3): 178-184, 2008

Table 2: Whole simulation results Historical record 1959-2001

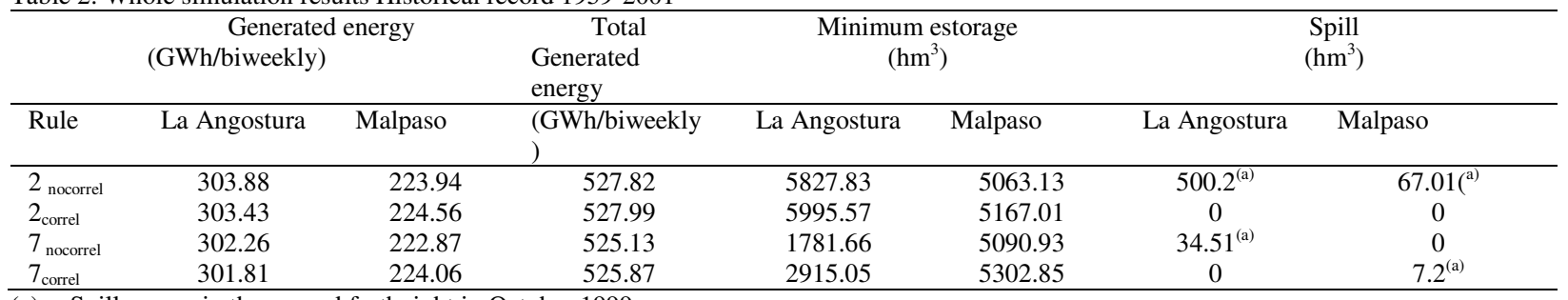

(a) Spill occurs in the second forthnight in October 1999

Studies made in 2004, taking data from 1959 to 2001, allows comparisons to be made between a policy which does not include operator needs (named in next Tables as policy 2) with and without autocorrelation included, and a policy which includes operator needs (named in next Tables as policy 7), with and without autocorrelation included during simulation. The results from these whole simulations are shown in Table 2.

Table 2 shows that additional restrictions set by the operators to carry out a light decrease of generated energy and a significant reduction of the minimum stored volume in the La Angostura Dam, with the risk of not being able of satisfy the demand (that means a deficit risk). The procedure proposed to take into account the correlation produces a little improvement in total generation, but it does generate an important increase in the minimum storage label (deficit risk is reduced).

Rule 7 guarantees a minimum outflow to the river with both benefits: ensured energy and ecologic flow downstream.

In 2005 huge floods took place on the Grijalva River. The La Angostura Dam reported daily mean inflow whose magnitude was about $13,000 \mathrm{~m}^{3} / \mathrm{s}$ on October the $6^{\text {th }}$; the largest ever recorded. Figure 3 shows a portion of that recorded flood. Due to the exceptional flood characteristics, it was considered necessary to update the design avenues in four dams and their operating rules. This includes generating a minimum in draught periods and trying to accommodate generated energy in peak hours.

With information provided by the CFE, historical inflow volumes to the La Angostura and Malpaso dams were updated. The total volume was calculated for each dam that covered all the stages in the year: stage 1 corresponds to November and December, stage 2 to October, stage 3 to September, stage 4 to August, stage 5 to June and July, and stage 6 from January to May.
Once the total volume by stage was obtained for each recorded year, data were ordered from higher to lower and frequency of data falling on each $\Delta \mathrm{V}(600$ million cubic meters) interval was obtained. Relative frequency was estimated by dividing each calculated quantity by the number (45) of data. A frequency histogram was obtained which was employed as the probability distribution function of biweekly inflows. Additionally, those results were streamlined to consider the possible existence of an event bigger than historically recorded. With the probabilities obtained for each stage, the stochastic dynamic programming algorithm was run and new operating policies were obtained.

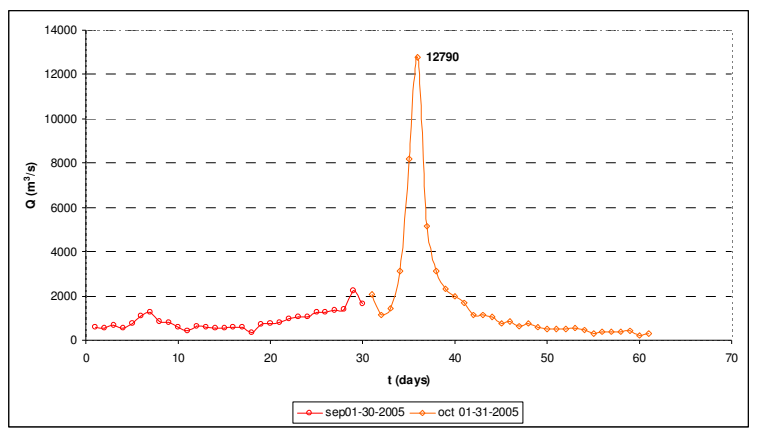

Fig. 3: Flood in La Angostura, September-October 2005

New simulations with historical records (19592005) were made, using operating rule 2 (does not take into account a minimum outflow), operating rule 7 , and the operating rule which takes into account the events of 2005 in the biweekly probabilities, and is called "New" in Table 3.

Historically generated and simulated energy values from 1991 to 2005 were drawn in Fig. 4 and Fig. 5. In addition, a comparison in generated average energy for the historical real operating rule and the simulated rule one was made on Table 4. 
Am. J. Environ. Sci., 4 (3): 178-184, 2008

Table 3: Whole simulation results after taking into account 2005 events. Historical record (1959-2005)

\begin{tabular}{|c|c|c|c|c|c|}
\hline & Affecting D & L coefficient & Generat & & Total Energy \\
\hline \multirow[t]{2}{*}{ Rule } & & & \multicolumn{2}{|c|}{ GWh/biweekly } & GWh/biweekly \\
\hline & CDV(Ang) & CDV(Malp) & La Angostura & Malpaso & Sum \\
\hline 2 no correl & 0 & 0 & 286.43 & 216.99 & 503.42 \\
\hline 7 & 0.75 & 1.5 & 295.25 & 218.11 & 513.36 \\
\hline New & 0.75 & 1.5 & 294.09 & 220.55 & 514.64 \\
\hline
\end{tabular}

Table 3: Continuation

\begin{tabular}{ccccc}
\hline \multirow{2}{*}{ Rule } & \multicolumn{2}{c}{ Minimum storage } & \multicolumn{2}{c}{ Spill } \\
& $\left(10^{6} \mathrm{~m}^{3}\right)$ & & La Angostura & Malpaso \\
\cline { 2 - 5 } & La Angostura & Malpaso & 0 & 0 \\
\hline 2 no correl & 0 & 4868.68 & 0 & 0 \\
7 & 1923.64 & 5236.11 & 0 & $6.97^{\text {(a) }}$ \\
\hline New & 1546.1 & 5824.47 & & 0 \\
\hline
\end{tabular}

(a) Spill in first fortnight of October 1970

Table 4: Generated average energy. Historical and Simulated values

\begin{tabular}{cccc}
\hline Dam & $\begin{array}{c}\text { Historical average } \\
(\mathrm{GWh} / \text { month })\end{array}$ & $\begin{array}{c}\text { Simulated average } \\
(\mathrm{GWh} / \mathrm{month})\end{array}$ & $\begin{array}{c}\text { Historical/Simulated } \\
(\%)\end{array}$ \\
\hline La Angostura & 552.07 & 542.75 & 101.72 \\
Malpaso & 404.06 & 407.16 & 99.24 \\
Sum & 956.13 & 949.91 & 100.65 \\
\hline
\end{tabular}

Table 3 clearly shows how spills are practically avoided with the three simulated rules, but rule 2 implies a deficit in La Angostura and the minimum generated energy and, therefore, minimum outflow to the Grijalva River is not generated during drought periods, as shown in Fig. 4 and Fig. 5.

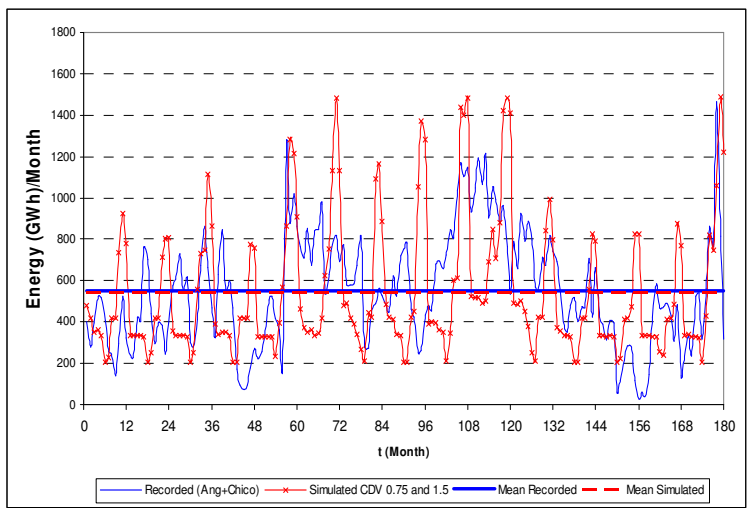

Fig. 4: Energy-Time (1991-2005) La Angostura

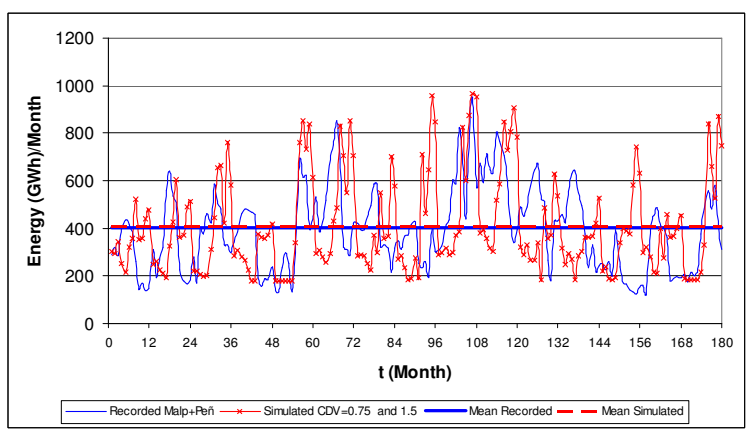

Fig. 5: Energy-Time (1991-2005) Malpaso

According to Table 4, during the whole simulated time period, the historical generation with the historical operating rule used by the system operators has been greater by only $0.65 \%$.

In order to observe the possible system function in the long term, ten synthetic series of 100 years were generated $^{[27,28]}$, and simulated with the new operating rule. The results are shown in Table 5. 
Am. J. Environ. Sci., 4 (3): 178-184, 2008

\begin{tabular}{|c|c|c|c|c|c|}
\hline & \multicolumn{2}{|c|}{$\begin{array}{c}\text { Energy } \\
\text { GWh/biweekly }\end{array}$} & \multirow{2}{*}{$\begin{array}{r}\text { Total Energy } \\
\text { GWh/biweekly } \\
\text { Sum }\end{array}$} & \multicolumn{2}{|c|}{$\begin{array}{c}\text { Spill } \\
\left(10^{6} \mathrm{~m}^{3}\right)\end{array}$} \\
\hline & La Angostura & Malpaso & & La Angostura & Malpaso \\
\hline Series 1 & 279.7 & 213.93 & 493.63 & 0 & 0 \\
\hline Series 2 & 301.74 & 225.48 & 527.22 & 0 & $395.7^{(\mathrm{a})}$ \\
\hline Series 3 & 286.04 & 216.13 & 502.17 & 0 & $36.06^{(\mathrm{b})}$ \\
\hline Series 4 & 297.64 & 223.52 & 521.16 & $2066.1^{(\mathrm{c})}$ & $2656.69^{(\mathrm{d})}$ \\
\hline Series 5 & 279.82 & 211.89 & 491.71 & 0 & 0 \\
\hline Series 6 & 301.8 & 225.92 & 527.72 & $1107.63^{(\mathrm{e})}$ & $3609.86^{(\mathrm{f})}$ \\
\hline Series 7 & 287.93 & 215.46 & 503.39 & 0 & $211.08^{(\mathrm{g})}$ \\
\hline Series 8 & 289.88 & 217.56 & 507.44 & 0 & $272.2^{(\mathrm{h})}$ \\
\hline Series 9 & 286.64 & 212.82 & 499.46 & 0 & $285.17^{(\mathrm{i})}$ \\
\hline Series 10 & 287.76 & 217.65 & 505.41 & $718.95^{(j)}$ & $2183.33^{(\mathrm{k})}$ \\
\hline Average & 289.895 & 218.036 & 507.931 & 389.268 & 965.009 \\
\hline
\end{tabular}

(a) Spill in years 85 and 86, fortnights with spill: 3

(c) Spill in years 11 and 12, fortnights with spill: 3

(e) Spill in years 66 and 67, fortnights with spill: 2

(g) Spill in year 77,fornight with spill: 1

(i) Spill in year 23, fornights with spill: 3

(k) Spill in years 24 and 61, fornights with spill: 4

\section{CONCLUSION}

The combination of stochastic dynamic programming to generate operating rules and the whole reservoir simulation allows for reviewing what could be system behavior under several operating rules. It provides information about total energy generated during a period of time and energy biweekly variation, as well as possible spill and possible deficit condition as well.

Environmental requirements of an ecological runoff in streams, especially those affected by serial dams, meet the need of detailed analysis in operating hydropower systems or multipurpose dams, the ultimate purpose is to balance man's needs with the remaining needs of ecosystems, and that is not a simple task.

This analysis generated new, flexible operating rules to reconcile different restrictions added by decision-makers to the Grijalva hydropower system and the corresponding minimum outflow needed by the Grijalva River's life forms.

\section{REFERENCES}

1. Fashchevsky, B. and T. Fashchevskaya, 2004. Ecological Hydrology: New Scientific Direction for Water Resources Management From http://www.wrrc.dpri.kyoto-u.ac.jp/ aphw/ APHW2004/proceedings/OHS/56-OHS-M162/56OHS-M162.pdf. Consulted on January, 2007.
2. Homa, E.S., R. M. Vogel, M.P Smith, C. D. Apse, A. Huber-Lee, and J. Sieber, 2005. An Optimization Approach for Balancing Human and Ecological Flow Needs. Proceedings of the EWRI 2005 World Water and Environmental Resources Congress, ASCE, Anchorage, Alaska.

3. Poff N.L., D.Allan, M.B. Bain, J.R. Karr, K.L. Prestegaard, B. D. Richter, R. E. Sparks and J.C. Stromberg, 1997. The Natural Flow Regime A paradigm for river conservation and restoration. BioScience 47 (11): 769-784.

4. Egré, D. and J. C. Milewski, 2002. The diversity of hydropower projects. Energy Policy 30: 12251230.

5. Collier, U., 2004. Hydropower and the environment: Towards better decision-making. Proceedings of Symposium on Hydropower and Sustainable Development, October 27-29 Beijing, China.

6. Krchnak, K. M., 2006. "Greening" Hydropower: Integrating Environmental Flow Considerations.From:http://www.nature.org/initiati ves/freshwater/files/hydropower_2006_

krchnak_paper_final.pdf. Consulted on January, 2007.

7. Trussart, S., D. Messier, V. Roquet and S. Aki , 2002. Hydropower projects: a review of most effective mitigation measures. Energy Policy 30: 1251-1259. 
8. Arfi, R., 2005. Seasonal ecological changes and water level variations in the Se'lingue' Reservoir (Mali, West Africa). Physics and Chemistry of the Earth 30: 432-441

9. Richter, B. and S. Postel, 2004. Saving earth's rivers. Issues in Science and Technology. Spring. 31-36.

10. Richter, B.D., R. Roos-Collins and A.C. Fahlund, 2005. A Framework for Ecologically Sustainable Water Management. Environmental Protection, Hydro Review.

11. Richter, B.D., A.T. Warner, J.L., Meyer and K. Lutz, 2006. A collaborative and adaptive process for developing environmental flow recommendations. River Res. Applic. 22: 297-318.

12. Yen, L.H , Y. Y. Hsu, B.S. Chang and K. K Chen, 1996. A Linear Programming Method For The Scheduling Of Pumped-Storage Units With Oscillatory Stability Constraints. IEEE Transactions on Power Systems, 11 (4): 1705-1710.

13. George B. Dantzig, 1998. Linear Programming and Extensions. Princeton University Press. Mathematics, USA, pp :1-31.

14. Dantzig, G.B.,2002. Linear Programming. Operations Research INFORMS. 50 (1): 42-47.

15. Cai, X., D.C. McKinney and L.S. Lasdon, 2001. Solving nonlinear water management models using a combined genetic algorithm and linear programming approach. Advances in Water Res. 24: 667-676.

16. Richard E. Bellman, 1957. Dynamic Programming. Princeton University Press. Princeton, New Jersey, USA, 366 p.

17. Lester R. Ford and D.R. Fulkerson, 1962. Flows in Networks. Princeton University Press, USA 194 pp.

18. Cunha, M. C., 1999. On Solving Aquifer Management Problems With Simulated Annealing Algorithms. J. Water Res. Manage. 13: 153-169.

19. S. V. N. Rao, B. S. Thandaveswara, S. Murty Bhallamudi, And V. Srinivasulu, 2003. Optimal Groundwater Management in Deltaic Regions using Simulated Annealing and Neural Networks. J. Water Res. Manage. 17: 409-428
20. Jared L. Cohon, 2004. Multiobjetive programming and planning. Courier Dover Publications, USA. $243 \mathrm{p}$.

21. Arganis, J. M.L., 2004. Operación óptima de un sistema de presas en cascada para generación hidroeléctrica, tomando en cuenta condiciones reales de operación y el uso de muestras sintéticas para el pronóstico. $\mathrm{PhD}$ Thesis, Universidad Nacional Autónoma de México, México.

22. Mousavi, S. J., K. Ponnambalam and F. Karray, 2005. Reservoir Operation Using A Dynamic Programming Fuzzy Rule-Based Approach. Water Res. Manage 19: 655-672

23. Alfieri ,L., P. Perona, and P. Burlando, 2006. Optimal Water Allocation for an Alpine Hydropower System Under Changing Scenarios. Water Res. Manage. (2006) 20: 761-778.

24. Domínguez, M. R. and R. R. Mendoza, 2000. Funcionamiento de las presas Angostura, Chicoasén, Malpaso y Peñitas sobre el río Grijalva, elaborado para la Comisión Nacional del Agua, por el Instituto de Ingeniería, UNAM, México.

25. Domínguez, M.R., R. R. Mendoza, C. A. Alvarado and L. E. Márquez, 1993. "Operación Integral del Sistema Hidroeléctrico del Río Grijalva”, elaborado para la CFE por el Instituto de Ingeniería, UNAM. México.

26. Domínguez, M.R., R. R Mendoza and C.C Contreras, 1998. Estudios hidrológicos de la segunda etapa del análisis Integral de la zona baja del río Grijalva. Política de operación del sistema de presas. Informe Preliminar, Instituto de Ingeniería, UNAM, México.

27. Givi G. Svanidze, 1980. Mathematical Modeling of Hydrologic Series, Water Resources Publicatons, USA. pp. 163-195.

28. Domínguez M, R., M. G. Fuentes and M. L. Arganis, 2001. Procedimiento Para Generar Muestras Sintéticas de Series Periódicas Mensuales a través del Método de Svanidze Modificado Aplicado a los Datos de las Presas La Angostura y Malpaso. Series Instituto de Ingeniería C1-19. Agosto. Serie Blanca. 